\title{
The effect of oil prices on the economic diversification process: Evidence from the GCC countries
}

\author{
Osama D. Sweidan* \\ Department of Innovation in Government and Society, United Arab Emirates University, United Arab Emirates
}

Received: 7 January 2020

Revised: 11 March 2020

Accepted: 4 May 2020

\begin{abstract}
We investigate the Granger non-causality relationship between oil prices and the economic diversification process in the GCC countries during the period 1989-2017. This paper uses Pedroni's (2004) panel cointegration tests and the panel non-causality test of Dumitrescu-Hurlin (2012). We find that oil price changes Granger cause the movements in the diversification progression. It indicates that economic diversification of the GCC countries is not a priority to the GCC governments because their role is changing. As a result, the GCC countries should give priority to economic diversification if it is a strategic plan for their economies.

Keywords: oil prices; economic diversification; panel analysis; Granger non-causality test; the GCC countries.

JEL Classification Codes: C23, Q01, Q28, Q35
\end{abstract}

\section{Introduction}

A long time ago, the Gulf Cooperation Council (GGC) ${ }^{1}$ economies realized that gas and oil resources are finite, and their prices fluctuate substantially, which creates unstable income and government budget deficits (Kubursi,1984). Hence, the international monetary fund (IMF) predicts fiscal and external breakeven oil prices to monitor the balances in these economies. Moreover, the extensive exploitation of natural resources crowds out the other economic sectors, which is known in literature as Dutch disease.

Recently, Al-Sarihi (2018) described economic diversification in the GCC economies as an essential choice to face the challenges of climate change and preserve the environment. It reduces the share of the hydrocarbon and related industries and therefore cuts the $\mathrm{CO} 2$ emissions. Without a doubt, greater diversification would reduce exposure to uncertainty in the

\footnotetext{
* Corresponding author. E-mail: osweidan@uaeu.ac.ae.

Citation: Sweidan, O. S. (2020) The effect of oil prices on the economic diversification process: Evidence from the GCC countries, Economics and Business Letters, 9(4), 334-341.

DOI: 10.17811/ebl.9.4.2020.334-341 ${ }^{1}$ The GCC economies consists of six countries: Bahrain, Kuwait, Oman, Qatar, Saudi Arabia, and the United Arab
Emirates.
} 
global oil market, increase productivity and sustainable development, and create private sector jobs. Consequently, the GGC countries announced economic diversification as a strategic economic policy a long time ago. Cherif and Hasanov (2016) pointed out some key elements to address the success of diversification. It includes changing the incentives structure for workers and firms. Besides, altering social attitudes toward investment in human capital, entrepreneurship, and employment in the private sector.

Unfortunately, the diversification accomplishments of the GCC economies are weak. Figure 1 presents the ratio of the oil and non-oil sectors to GDP of the GCC countries during the period 1980-2017. The ratio of the hydrocarbon sector to GDP has increased in some countries, i.e., Kuwait and Qatar, and almost the same in other countries, i.e., Saudi Arabi and Oman. The only exception is the UAE, where the relative importance of the sector has decreased.

Many scholars, i.e., Hvdit (2013) and Djimeu and Omgba (2019), stated that oil price is a critical economic variable in the success of economic diversification. Therefore, paper's goal is to empirically investigate the existence of a bivariate causality from oil price to economic diversification in the six GGC economies during the period 1989-2017. Logically, if there are stable governments' plans to diversify the economies, then the oil price changes should not have a causality effect on the economic structure. The existence of a causality effect indicates that the oil price fluctuations alter the GCC governments' decisions. We use panel data to obtain more observations and powerful causality test. Our study contributes to recognize the influence of oil price variations on the structure of the GCC economies and the choices of the economic policymakers.

\section{Literature review}

The interest in oil price effects on the economy has aggravated after the Arab oil embargo of 1973. Over time, scholars agreed that oil prices influence oil exporting and importing countries alike. Oil price volatility and rapid increase in the domestic labor force in the GCC countries call for a sustained increase in non-oil GDP. As a result, these countries announced that economic diversification is a strategic objective for them. Some studies, i.e., Hvdit (2013), pointed to oil prices as the core reason for the weak accomplishments of economic diversification in these countries. ${ }^{2}$

The institutional support to the economic diversification process is essential and fluctuates with oil price; when the price of oil increases, the emphasis on the economic diversification decreases. It is related to the state of power (impotence) of the GCC governments may have, if the oil price increases (decreases). Put it differently, it means there is a trade-off between oil price and the economic diversification process. Figure 2 introduces the normalized changes in the relative importance of the non-oil sector to GDP in the GCC economies and the change in oil prices. It provides remarkable evidence about the relationship between the two variables. It reveals that the relationship between the two variables became clearer and negative starting from 1996.

In the same vein, some researchers, i.e., Bremmer (2009), Gray (2011), Tok (2018), considered the existence of massive wealth via high oil prices had changed the GCC governments role to be the most influential player in the economy. They have established the Entrepreneurial State Capitalist to achieve regime security and stability. If this hypothesis or statement is correct, then oil prices Ganger cause the diversification process. It means that economic diversification is a target when the oil prices are low.

\footnotetext{
${ }^{2}$ For more reasons for the weak diversification performance in the GCC countries, see Hvdit (2013), pp. 14-16.
} 
Figure 1. The share of oil and non-oil sectors to GDP in the GCC countries.
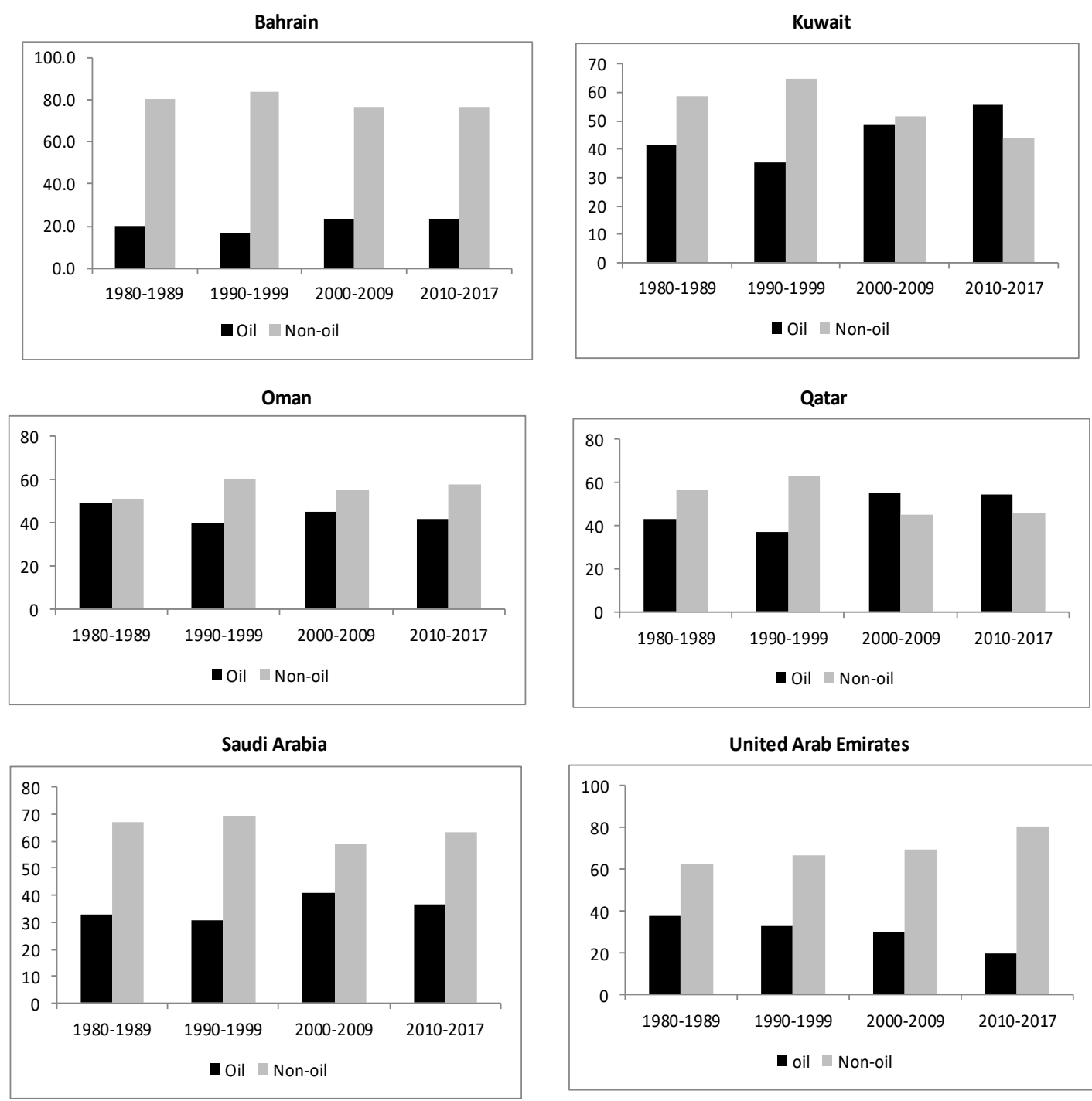

Source: The national accounts of each country and Quandl website.

Figure 2. The normalized changes in the ratios of the non-oil sector to GDP in the GCC economies and the change in the oil prices.

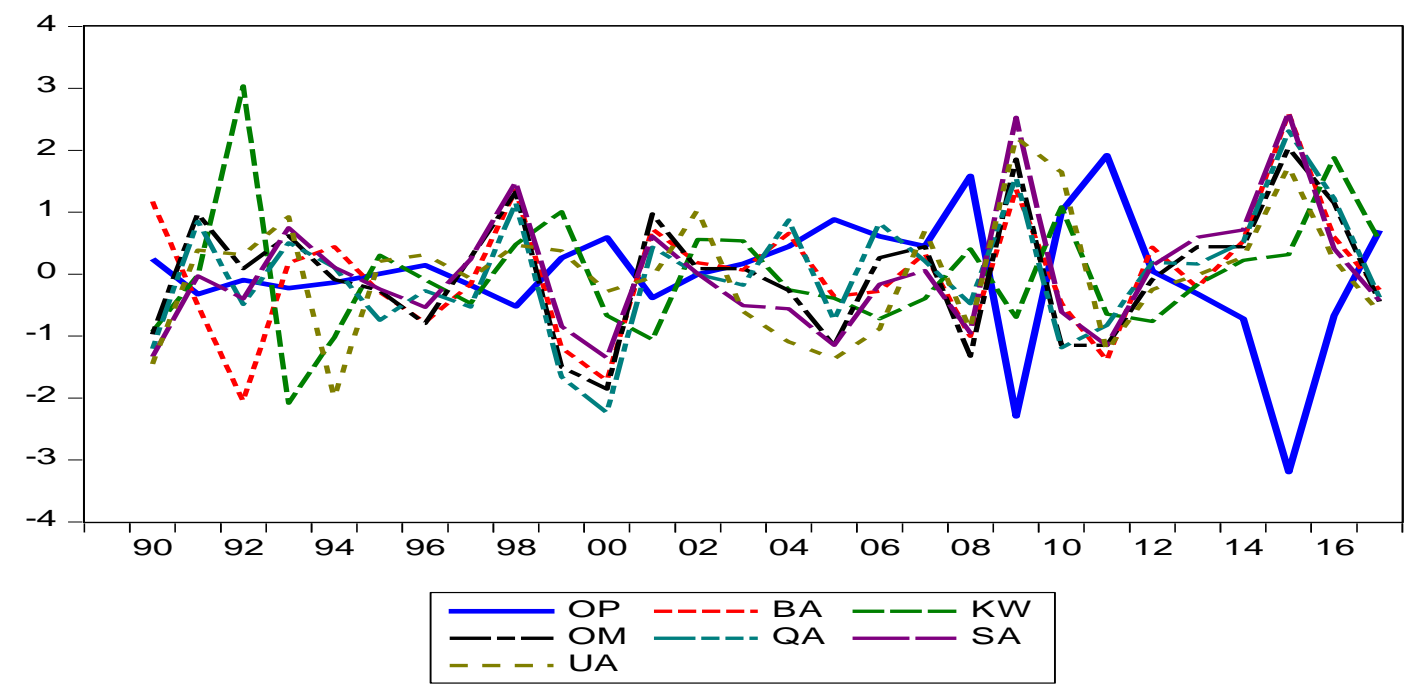


Table 1. Data descriptive statistics.

\begin{tabular}{lrr}
\hline \hline & Non-oil GDP & Oil price \\
\hline Mean & 4.13 & 3.57 \\
Std. Dev. & 0.21 & 0.69 \\
Kurt. & -0.15 & -1.37 \\
Skew. & -0.56 & 0.28 \\
Min. & 3.55 & 2.51 \\
Max. & 4.52 & 4.70 \\
Obs. No. & 174 & 174 \\
\hline \hline
\end{tabular}

Recently, Djimeu and Omgba (2019) empirically examined the influence of oil booms on export diversification in a sample of 134 countries. They concluded that oil booms adversely impact export diversification only if countries initially exhibit low levels of diversification. However, in economies with a high diversification level before the boom, oil booms do not affect diversification. Contrary to their study, this paper focuses on the GCC countries, and we test different argument with different variables. Besides, we use different methodologies.

\section{Data and methodology}

We extract our data of the six GCC countries from three sources. The sectoral GDP from the national accounts of each country and quandl website, while the oil prices from the World Bank data via the data stream. The data covers the period 1989-2017 for the six GCC economies. Thus we have 174 observations. We transform the data by using the natural logarithm. Table (1) presents the descriptive statistics of our data.

Within the framework of the announced goal of this paper, our empirical plan has two steps. First, we test whether a long-run relationship exists between the two variables using Pedroni's (2004) panel cointegration tests. Second, if there is no cointegration relationship between the two variables, we will perform the panel non-causality test of Dumitrescu-Hurlin (2012) (hereafter DH).

\subsection{Pedroni's heterogeneous panel cointegration tests}

Pedroni's cointegration tests are based on the estimated residuals from the following long-run model:

$$
\begin{gathered}
Y_{i t}=\mu_{i}+\theta_{i} T+\sum_{j=1}^{k} \gamma_{j i} X_{j i t}+u_{i t} \\
u_{i t}=\rho_{i} u_{i(t-1)}+\varepsilon_{i t}
\end{gathered}
$$

Subscript $i$ denotes each unit of the analysis. Subscript $t$ represents the time. $Y_{i t}$ and $X_{i t}$ are the variables of the long-run regression model and assumed to be integrated of order one, i.e., I (1), $\mu_{i}$ is the unit-specific intercept, $\theta_{i}$ is the individual trend effect, $T$ is the time trend, and $u_{i t}$ and $\varepsilon_{i t}$ are the unit-specific disturbances of the long-run and auxiliary regressions, respectively. Pedroni's tests allow for heterogeneous intercepts and trend coefficients across sections. The $H_{0}$ of Pedroni's tests states no cointegration between the variables $\left(\rho_{i}=1\right)$. If the cointegration tests are statistically significant (low p-values), we can reject $H_{0}$. It means a long-run relationship between the variables exist $\left(\rho_{i}<1\right)$. However, if the cointegration tests are statistically insignificant (high p-values), we cannot reject the null hypothesis; there is no longrun relationship between the variables $\left(\rho_{i}=1\right)$. 


\subsection{DH test of non-causality}

DH provide an extension on Granger (1969) methodology to detect causality in panel data. Consider the underlying regression:

$$
Y_{i, t}=\alpha_{i}+\sum_{k=1}^{K} \varphi_{i k} Y_{i, t-k}+\sum_{k=1}^{K} \omega_{i k} X_{i, t-k}+v_{i, t}, i=1, \ldots, N, \text { and } t=1, \ldots, T
$$

Subscripts $i$ and $t$ the same as in Eq (1). $Y_{i, t}$ and $X_{i, t}$ are the variables of the regression and assumed to be stationary. $\alpha_{i}$ is the individual intercept. $\varphi_{i k}$ and $\omega_{i k}$ are the coefficients of the model and they allowed to differ across the countries but are assumed time-invariant. The null hypothesis of the DH test is the absence of causality for all the countries in the panel, and can be defined as follows:

$$
H_{0}=\omega_{i 1}=\omega_{i 2}=\cdots=\omega_{i k}=0, \forall i=1, \ldots, N
$$

For the alternative hypothesis, DH test assumes there is a causality for some countries but not necessarily for all. Hence, it can be defined as follows:

$$
H_{1}=\omega_{i 1}=\omega_{i 2}=\cdots=\omega_{i k}=0, \forall i=1, \ldots, N_{1}
$$

$N_{1}$ must be strictly smaller than $\mathrm{N}$.

Or

$$
H_{1}=\omega_{i 1} \neq 0 \text { or } \omega_{i 2} \neq 0 \text { or } \ldots \ldots \text { or } \omega_{i k} \neq 0, \forall i=N_{1}+1, \ldots, N
$$

$N_{1}$ must be strictly smaller than $\mathrm{N}$ and does not equal to zero. If $N_{1}=0, H_{1}$ is reduced to $H_{0}$. Rejecting $H_{0}$ does not exclude non-causality for some units. Empirically, DH test rely on calculating the Wald statistics $\left(W S_{i}\right)$ for each individual country from regression (3), then computing the average Wald statistics $(\bar{W})$ as follows:

$$
\bar{W}=\frac{1}{N} \sum_{i=1}^{N} W S_{i}
$$

For the standardized statistics ( $\bar{Z}$ and $\tilde{Z}$ ), under the assumption that the $W S_{i}$ are i.i.d across countries, DH showed that when $\mathrm{T}$ first approaches infinity and then $\mathrm{N}$ approaches infinity, the standardized $\bar{Z}$ follows a standard normal distribution as follows:

$$
\bar{Z}=\sqrt{\frac{N}{2 K}} *(\bar{W}-K) \quad \stackrel{d}{\underset{T, N \rightarrow \infty}{\longrightarrow}} \quad N(0,1)
$$

For a fixed $\mathrm{T}$ dimension with $\mathrm{T}>5+3 \mathrm{~K}$, the standardized statistic $\tilde{Z}$ follows a standard normal distribution as follows:

$$
\tilde{Z}=\sqrt{\frac{N}{2 K} * \frac{(T-2 K-5)}{(T-K-3)}} *\left[\frac{(T-2 K-3)}{(T-2 K-1)} *(\bar{W}-K)\right] \quad \underset{N \rightarrow \infty}{\stackrel{d}{\longrightarrow}} \quad N(0,1)
$$

Testing the null hypothesis of DH test relies on the values of $\bar{Z}$ and $\tilde{Z}$. If their values are larger than the standard critical value, then $H_{0}$ should be rejected.

The DH test has the following features. First, it assumes the dynamic of the variables is heterogeneous for all the individuals in the sample. Second, DH test is more powerful than tests based on a single time series even in a panel with very few cross-section units.

\section{The results}

First, we check the stationarity of our variables. The two variables should be integrated of order one. We employ three unit root tests; Im- Pesaran-Shin (IPS), Breitung, and Hadri LM. We report the results of the unit root tests in Table 2. The two variables are stationary at the first difference. Hence, we can proceed and conduct Pedroni's tests. We report Pedroni's tests in 
Table 2. Panel unit root tests.

\begin{tabular}{lrrr}
\hline \hline Panel A: level & & & \\
\hline & IPS & Breitung & Hadri \\
Non-oil GDP & 0.52 & 0.72 & $11.07^{* * * *}$ \\
Oil price & -0.10 & -0.12 & $10.69^{* * *}$ \\
\hline Panel B: first difference & & & -0.23 \\
\hline Non-oil GDP & $-7.52^{* * * *}$ & $-4.83^{* * *}$ & -0.77 \\
Oil price & $-7.25^{* * *}$ & $-2.36^{* * *}$ & \\
\hline$* * *: \mathrm{p}<0.01$ & & &
\end{tabular}

Table 3. Pedroni's heterogeneous panel cointegration test results.

\begin{tabular}{lrrrrr}
\hline \hline & Within-dimension & \multicolumn{3}{c}{ Between-dimension } \\
\hline Test Statistics & Value & Weighted Test Statistics & Value & \multicolumn{1}{c}{ Test Statistics } & Value \\
\hline Panel v-stat & 0.36 & Panel v-stat & 0.38 & Group rho-stat & 1.21 \\
Panel rho-stat & 0.42 & Panel rho-stat & 0.48 & Group PP-stat & -0.19 \\
Panel PP-stat & -0.70 & Panel PP-stat & -0.52 & Group ADF-stat & -0.10 \\
Panel ADF-stat & -1.06 & Panel ADF-stat & -0.58 & & \\
\hline \hline
\end{tabular}

Notes: Individual trend and individual intercept are included in the tests. The optimal lag length was automatically selected based on the AIC with a maximum 8 lags. Newey-West automatic bandwidth was selected based on a Bartlett kernel.

Table 4. DH test results.

\begin{tabular}{crrrrrrr}
\hline \multicolumn{1}{l}{ Panel A: The author picked-up the lags } \\
\hline \multicolumn{1}{c}{ Lag 1 } & \multicolumn{1}{l}{ Lag 2 } & Lag 3 & Lag 4 & Lag 5 & Lag 6 & Lag 7 \\
$\bar{W}$ & 6.69 & 8.64 & 10.77 & 18.18 & 20.25 & 37.97 & 46.72 \\
$\bar{Z}$ & $9.86^{* * *}$ & $8.13^{* * * *}$ & $7.77^{* * *}$ & $12.28^{* * *}$ & $11.82^{* * *}$ & $22.61^{* * *}$ & $26.01^{* * *}$ \\
$\tilde{Z}$ & $8.30^{* * *}$ & $6.41^{* * *}$ & $5.65^{* * *}$ & $8.19^{* * *}$ & $6.72^{* * *}$ & $10.32^{* * *}$ & $6.74^{* * *}$ \\
\hline
\end{tabular}

Panel B: Optimal lag is 1 based on AIC (lags tested: 1 to 7)

\begin{tabular}{cc} 
Panel B: Optimal lag is 1 based on AIC (lags tested: 1 to 7$)$ \\
\hline & Lag 1 \\
$\bar{W}$ & 6.69 \\
$\bar{Z}$ & $9.86^{* * * *}$ \\
$\tilde{Z}$ & $8.30^{* * *}$ \\
\hline
\end{tabular}

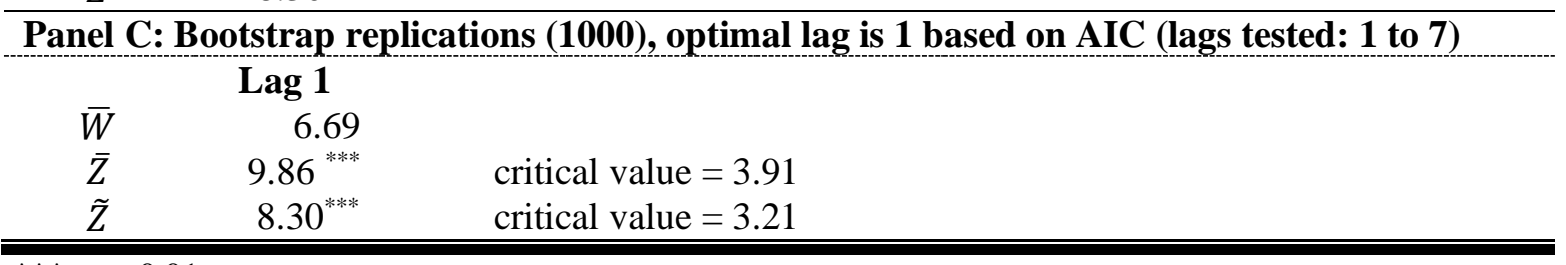

$* * *: \mathrm{p}<0.01$.

Based on the rule $\mathrm{T}>5+3 \mathrm{~K}$, the maximum lag is 7 .

Table 3. They reveal that we cannot reject the null of no cointegration for all tests. Hence, our results confirm that oil price and non-oil GDP ratio do not share a long-run cointegrating relationship in the GCC economies. Thus, we proceed to conduct DH test.

We estimate the DH test by using the xtgcause command from Stata software, as explained by Lopez and Weber (2017). We report the outcomes of DH test in Table 4. The results have three dimensions. First, panel A, where the author used all the available lags; the maximum available lags is 7 . From this dimension, we can reject the null hypothesis for all the lags. Thus, our results provide evidence that oil price changes Granger cause non-oil GDP ratio movements. Second, panel B, where the optimal lags selected automatically by minimizing AIC; the optimal lag is one. Panel B result confirms the outcomes of panel A; we can reject the 
Table 5. Sensitivity analysis: DH test results.

\begin{tabular}{crrrrrrr}
\hline \hline Panel A: The author picked-up the lags & & & & \\
\hline & Lag 1 & Lag 2 & Lag 3 & Lag 4 & Lag 5 & Lag 6 & Lag 7 \\
$\bar{W}$ & 9.88 & 12.04 & 14.96 & 25.53 & 29.05 & 53.97 & 65.53 \\
$\bar{Z}$ & $12.55^{* * * *}$ & $10.04^{* * *}$ & $9.76^{* * *}$ & $15.22^{* * * *}$ & $15.21^{* * *}$ & $27.69^{* * * *}$ & $31.28^{* * * *}$ \\
$\tilde{Z}$ & $10.62^{* * * *}$ & $8.00^{* * *}$ & $7.22^{* * *}$ & $10.31^{* * *}$ & $8.87^{* * *}$ & $12.88^{* * *}$ & $8.36^{* * *}$ \\
\hline
\end{tabular}

Panel B: Optimal lag is 1 based on AIC (lags tested: 1 to 7)

\begin{tabular}{cr} 
& Lag 1 \\
$\bar{W}$ & 9.88 \\
$\bar{Z}$ & $12.55^{* * *}$ \\
$\tilde{Z}$ & $10.62^{* * *}$ \\
\hline
\end{tabular}

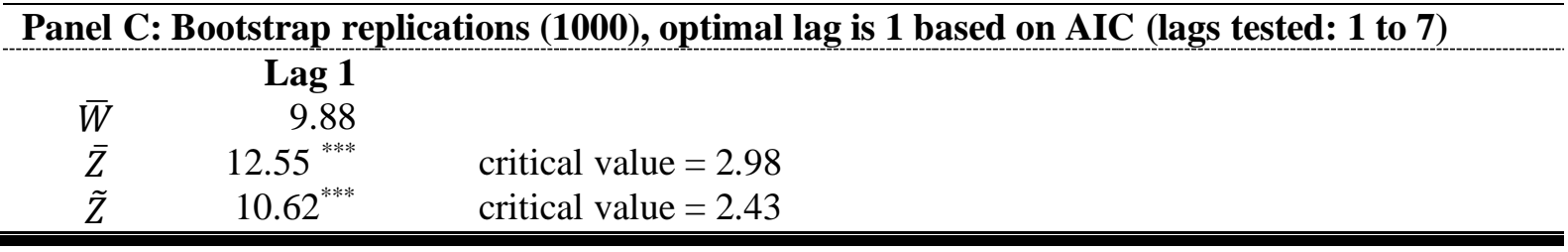

Notes: $* * *: \mathrm{p}<0.01$. Based on the rule $\mathrm{T}>5+3 \mathrm{~K}$, the maximum lag is 7 .

null hypothesis. In panel $\mathrm{C}$, we perform a bootstrap procedure with 1000 replication, and we have identical results to panel B. All the panels confirm that oil price changes Granger cause non-oil GDP ratio movements.

To examine the robustness of our results, we conduct a sensitivity analysis for the results. We execute this analysis by re-estimating the DH test for our data sample excluding two countries; Bahrain and Oman. We report the sensitivity analysis results in Table 5. The outcomes of the sensitivity analysis are identical to the original results; it approves that oil price changes Granger cause non-oil GDP ratio movements. It also confirms that our estimation is robust.

\section{Conclusions and policy implications}

This paper investigates the effect of oil price on the diversification process in the GCC countries during the period 1989-2017. Specifically, it tests the causality between oil prices and the share of the non-oil GDP in the economy. Implicitly, it indicates that the oil prices' fluctuations have changed the GCC governments role to be the most influential player in the economy, and thus slow down the diversification process in the region. Our paper provides evidence that oil price changes Granger cause non-oil GDP ratio fluctuations. It indicates that the economic diversification of the GCC economies is not a priority for their governments. The GCC countries should give priority to the economic diversification if it is a strategic plan for their economies.

\section{Acknowledgments}

The author would like to thank the editor and two anonymous referees of the Economics and Business Letters for their valuable and helpful comments. We are responsible for any errors.

\section{References}

Al-Sarihi, A. (2018) Prospects for climate change integration into the GCC economic diversification strategies. LSE Middle East Center. Paper series 20, February. London School of Economics and Political Science, London, UK. 
Bremmer, I. (2009) State capitalism comes of age, Foreign Affairs, 88(3), 40-55.

Breitung, J. (2001) The local power of some unit root tests for panel data, Baltagi, B., Fomby, T. and Carter Hill, R. (Ed.) Nonstationary Panels, Panel Cointegration, and Dynamic Panels, Advances in Econometrics, 15, 161-177.

Cherif, R. and Hasanov, F. (2014) Soaring of the Gulf falcons: diversification in GCC oil exporters in seven propositions. International Monetary Fund. IMF working paper, WP/14/177, September, Washington, DC.

Djimeu, E. W. and Omgba, L. D. (2019) Oil windfalls and export diversification in oilproducing countries: evidence from oil booms, Energy Economics, 78 (February), 494-507.

Dumitrescu, E-I. and Hurlin, C. (2012) Testing for Granger non-causality in heterogeneous panels, Economic Modelling, 29 (4), 1450-1460.

Granger, C. W. (1969) Investigating causal relations by econometric models and cross-spectral methods, Econometrica 37(3), 424-438.

Gray, M. (2011) A theory of late rentierism in the Arab States of the Gulf. Center for International and Regional Studies 7; Doha: Georgetown University School of Foreign Service in Qatar.

Hadri, K. (2000) Testing for stationarity in heterogeneous panel data, Econometrics Journal, $3(2), 148-161$

Hvidt, M. (2013) Economic diversification in GCC countries past record and future trends. Research Paper. Kuwait Programme on Development, Governance and Globalisation in the Gulf States. London School of Economics and Political Science, London, UK.

Im, K. S., Pesaran, M., and Shin, Y. (2003) Testing for unit roots in heterogeneous panels, Journal of Econometrics, 115(1), 53-74.

Kubursi, A. A. (1984) Oil, Industrialization and Development in the Arab Gulf States. London: Croom Helm.

Lopez, L. and Weber, S. (2017) Testing for Granger causality in panel data. The Stata Journal, 17(4), 972-984.

Pedroni, P. (2004) Panel cointegration: asymptotic and finite sample properties of pooled time series tests with an application to the PPP hypothesis, Econometric Theory, 20 (3), 597-625.

Tok, M. E. (2018) Can GCC states achieve sustainable economic diversification and development. Center for the Middle East, Rice University's Baker Institute for Public Policy. Houston, Texas. 